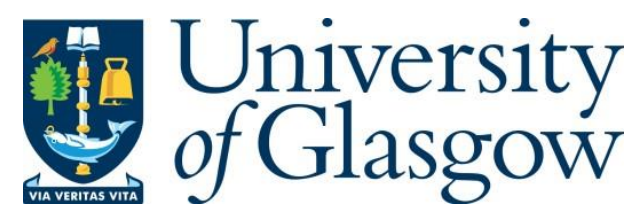

Rico, G. and Liñeira, R. (2018) Pass the buck if you can: how partisan competition triggers attribution bias in multilevel democracies. Political Behavior, 40(1), pp. 175196.

There may be differences between this version and the published version. You are advised to consult the publisher's version if you wish to cite from it.

$\underline{\text { http://eprints.gla.ac.uk/219963/ }}$

Deposited on: 16 July 2020

Enlighten - Research publications by members of the University of Glasgow http://eprints.gla.ac.uk 


\section{Pass the Buck If You Can: How Partisan Competition Triggers Attribution Bias in Multilevel Democracies}

\section{Introduction}

Retrospective voting theory depicts elections as a reward-punishment tool by which voters re-elect governments that perform well or throw out those who perform poorly (Key 1966; Powell 2000). However, this sanctioning mechanism relies on the fundamental assumption that voters are able to properly attribute responsibility for policy making to the incumbent government; yet, proper blame attribution is known to be compromised by institutional and motivational factors. The link between policy performance and vote choice is moderated by the clarity of responsibility of institutions: different political contexts generate varying degrees of difficulty for citizens in attributing responsibility for policy performance. It has been shown that divided power settings blur the lines of responsibility and make it harder for voters to hold governments accountable (Anderson 2000; Powell and Whitten 1993; Whitten and Palmer 1999).

In addition to the challenges posed by the institutional context, retrospective voting may be hindered by voters' propensity to bring responsibility judgments in line with their group attachments. When allocating responsibility, individuals are often motivated by a desire to place the groups they feel attached to in a good light. Accordingly, partisanship, perhaps the most common feeling of group attachment in the political domain, has been found to influence strongly blame attributions: partisans tend to claim credit for economic success to "their" party and shift blame for economic failures away from it and to the opposition (Hobolt and Tilley 2014; Rudolph 2003a, 2003b, 2006; Tilley and Hobolt 2011). 
While it has been widely acknowledged that institutional complexity hinders voters from attributing responsibility correctly, it has been much less appreciated how divided control over policymaking also offers voters to engage in motivated responsibility attribution based on group identities. We argue that the institutional dispersion of power not only makes it harder for citizens to know which institution is responsible for policy outcomes, but also facilitates individuals' rationalization of blame attributions. Namely, by allowing power to be shared among different parties, dispersed institutional control promotes the influence of partisan and other group attachments on responsibility judgments, which may further reduce the relationship between policy performance and incumbent support. The two processes have similar observable implications-i.e., low clarity of responsibility weakening retrospective voting — but imply markedly different micro-mechanisms at work. In the former scenario, the weak economic vote is due to voters' inability to attribute responsibility accurately in a complex institutional setting. In the latter scenario, however, the same complex institutional settings facilitate motivated rationalizations that allow citizens to "pass the buck." In short, we argue that these two processes - related to citizens' cognitive ability and motivated reasoning, respectively_ can unfold in parallel to weaken the retrospective vote. Although sometimes implied by previous research (e.g., Brown 2010; Parker-Stephen 2013), this latter proposition has rarely been put to a direct test.

This paper attempts to do so by examining the formation of responsibility judgments in multilevel democracies, where the vertical division of power has been shown to weaken responsibility linkages (Anderson 2006). In federations and other decentralized systems, subnational conditions may be seen as the responsibility of either regional governments or the national executive. We claim that whether voters adjust their attributions of responsibility according to their group attachments crucially depends on which parties are in control of the national and regional governments. Our focus is on the influence of partisan and territorial attachments, both of which constitute powerful markers that 
allow voters to distinguish governments in "us vs. them" terms. We advance the argument that group identifications towards parties and territories will bias attributions of responsibility only when the regional government and the national government belong to different parties that represent a relevant ingroup-outgroup conflict.

We test this claim using data from one national survey experiment and five regionally representative surveys in Spain. In having achieved a remarkable degree of autonomy and displaying a variety of partisan configurations, Spanish regions offer an ideal context to test our argument. In line with expectations, we find that partisan bias is confined to contexts where different levels of government belong to different parties. We also find that attribution bias on the basis of territorial identities is restricted to regions where the government is controlled by a regional nationalist party seeking to advance a distinct national identity and promoting greater autonomy or even independence for the region. These findings have important implications for explaining variations in the strength of retrospective voting both across and within institutional contexts.

The remaining of the article is organized as follows. In the following section, we put forward our theoretical argument and present our main hypotheses concerning the prevalence of attribution bias across partisan contexts. After briefly outlining the empirical strategy, we show the analyses of the experimental and observational studies. The last section summarizes the findings and discusses their implications.

\section{Attribution Bias and the Partisan Context}

Fiscal federalism literature has stressed the potential of federalism to enhance accountability and representation (Downs 1999, pp. 94-98; Rodden 2004). The existence of different levels of government, each one with its own functional 
responsibilities, would bring power closer to the people, leading to a more informed electorate on the policies carried out by the public authorities. All of this would translate into a more knowledgeable scrutiny by voters who may reward or punish the different officeholders for their respective policy responsibilities at the specific-level elections.

In contrast to these views, empirical evidence shows that multilevel polities may hinder the attribution of responsibilities. Contexts of vertically divided power introduce the "which level is responsible" question absent in unitary polities, particularly when different administrations share responsibilities in a policy area (León 2011). Although the assessment of the public's knowledge of policy responsibilities is mixed, both optimistic and pessimistic accounts share the view that the attribution of responsibilities is a daunting task in federal contexts, which reveals substantial variation in the citizens' perceptions of who is responsible for what (Arceneaux 2006; Cutler 2004, 2008; Gomez and Wilson 2008; Hobolt and Tilley 2014; Johns 2011).

In addition to information and cognitive barriers, the formation of accurate responsibility judgments is further hampered by ingroup attribution bias. Individuals' discrepancies on who is to be held responsible are largely conditional on their group identities. Social psychologists have long argued that the way individuals assign credit and blame is marked by a number of biases motivated by a desire to understand and predict events but also by a need to protect or enhance one's self-concept and selfesteem (Fiske and Taylor 1991). Typically, individuals accept credit for success and deny responsibility for failure, incurring "self-serving attribution bias". Such bias is usually extended to include the groups that individuals identify with in order to maintain a positive sense of self-esteem from group membership in the so-called "group-serving attribution bias" (Tajfel and Turner 1979; Taylor and Doria 1981). Along similar lines, the theory of motivated reasoning posits that people's processing of information is driven by two conflicting goals: accuracy goals, which motivate individuals to reach the "correct" conclusion; and directional goals, which motivate them to reach the preferred 
conclusion, in line with prior beliefs (Kunda 1990). Work in public opinion shows group-related cues regularly trigger directional goals and in turn bias individuals' political perceptions, evaluations, and choices (Taber and Lodge 2006).

Partisanship is perhaps the paramount group attachment informing directional goals in democracies (Campbell et al. 1960). Consistently, a recurrent finding in research on attributions of responsibility is that voters feeling attached to a party assign credit and blame in a partisan manner. Specifically, partisan voters appear to balance two considerations when forming responsibility judgments: who is in office (their party or another party) and how things are going in that policy domain (are conditions good or bad). If one's party is in charge, responsibility is put on the government when conditions are perceived to be good and elsewhere when conditions are perceived to be bad; similarly, opposition supporters will tend to blame the government when conditions are bad and dispute its credit when conditions are good. Such pattern of partisan disagreement in perceptions of incumbent responsibility has found ample support in the empirical literature (Bisgaard 2015; Gomez and Wilson 2001, 2003; Hobolt, Tilley, and Wittrock 2013; Hobolt and Tilley 2014; Malhotra 2008; Malhotra and Kuo 2008; Marsh and Tilley 2010; Nawara 2015; Peffley and Williams 1985; Rudolph 2003a, 2003b, 2006; Sirin and Villalobos 2011; Stein 1990; Tilley and Hobolt 2011).

As already noted, the attribution process is necessarily twisted in contexts of divided power, since responsibility for policy outcomes at the subnational level can arguably be ascribed to more than one institution. Still, an obvious, if sometimes overlooked qualification is that the institutional division of powers distorts responsibility attributions not only because the government is shared among different institutions, but also because this allows the government to be shared among different parties. This makes a huge difference, because, as Hobolt et al. (2013, p. 165) point out, "voters are less concerned with identifying which part of the political system is responsible than 
with identifying a single political party that they can reward or punish." When levels of government are controlled by different parties, voters are given the opportunity to blame parties by allocating responsibility between institutions, thereby encouraging the rationalization of responsibility judgments on the basis of partisan allegiances. Contrarily, when responsibilities are divided institutionally but shared among officials from the same party, clarity of responsibility—i.e. "perceived unified control of policymaking" (Powell and Whitten 1993, p. 398) — is actually high, and there is less room for the motivated bias of attributions. Partisan motivated reasoning is activated by competition between parties (Druckman et al. 2013; Rudolph 2006). Hence it is the partisan division of power which facilitates the rationalization of attributions.

In sum, we expect that the influence of partisanship on responsibility judgments will vary consistently with both the partisan context and perceptions of the policy conditions. In a multilevel setting, this implies that the partisan rationalization of attributions on the basis of perceptions of the regional conditions should be confined to contexts where the regional government is controlled by an out-party incumbent, that is, a party other than the national government's party. When the regional government is controlled by an in-party incumbent (i.e., belongs to the same party as the national incumbent) no partisan differentiation should emerge in the attribution of responsibility between levels of government.

Hypothesis 1. Partisan-based attribution bias will be restricted to regions with out-party incumbents; in such contexts, partisan differences in attributions will vary systematically with perceptions of the regional economy, such that the closer the voters feel to the regional incumbent the more willing they are to put the responsibility for positive outcomes on the regional government vis-à-vis the national government. 
This same rationale may be extended to other types of group attachment. Regions provide an additional basis for powerful and enduring group identifications, particularly when regional divisions overlap ethnic or linguistic boundaries (Fitjar 2010). Regional and national identities might link individuals to distinctive decentralization preferences and eventually to alternative national projects, represented by region-specific parties (Chernyha and Burg 2012). The existence of regional entities along with a national government makes it possible for feelings toward the corresponding territorial communities to come into play.

Compared to research on partisan attribution bias, few studies have explicitly examined the effects of territorial identities on responsibility judgments in federations. An exception is research showing that voters' adjustment of their perceptions of responsibility between the domestic and European institutions to performance evaluations is contingent on their feelings toward the European Union-which are, to a large extent, informed by national identity (Hobolt, Tilley, and Wittrock 2013; Hobolt and Tilley 2014). In multilevel settings with contending territorial identities, feelings of attachment to distinctive territorial communities may consequently be thought to bias attributions in a way very much like partisan identities: individuals who feel predominantly attached to their region will tend to deny the central government any responsibility for positive outcomes and blame it for negative outcomes, while individuals predominantly attached to the nation will be more willing to blame the regional government for failures and shift credit for success from the regional to the central government.

It might be argued that attribution bias related to territorial identities does not require partisan division to be activated, since attachment to territorial communities directly links citizens to the corresponding levels of government independently of which parties are in office. This might arguably be the case in regions with pervasive alternative national identities, like Quebec, Scotland, or Catalonia. However, even in such 
instances, people with exclusive territorial identities have few reasons to defend a government controlled by a party that does not share their national project. If, as just argued, the influence of group-based predispositions on political perceptions is triggered by conflict between political actors representing those groups, we should expect that the influence of territorial identities on attributions will be activated in contexts where the regional government is controlled by a regional nationalist party_-an out-party incumbent by definition. ${ }^{1}$ It is precisely in these contexts where voters can more easily connect a specific level of government with a particular in- or outgroup, i.e., they can associate each tier of government with the promotion of the interests of alternative national groups. By making the center-periphery divide more salient, nationalist governments should prompt the influence of territorial identities on attributions of responsibility.

Hypothesis 2. Attribution bias on the basis of territorial identities will be confined to regions with nationalist incumbents; in such contexts, differences in attributions between identity groups will vary systematically with perceptions of the regional economy, such that the closer the voters feel to the region the more willing they are to put the responsibility for positive outcomes on the regional government vis-à-vis the national government.

\section{Empirical Strategy}

\section{Case Study}

The Spanish State of Autonomies provides a key test for the previous hypotheses. The Spanish regions share a similar institutional setting, but are heterogeneous in terms of

\footnotetext{
${ }^{1}$ For ease of presentation, we henceforth use the unqualified term "nationalist" to refer only to regional nationalist parties, i.e. region-specific parties that claim nationhood for a region and aim to empower it by promoting self-government or independence. See Hepburn (2009) for a discussion of the different labels used to classify this party family in the literature.
} 
the regional governments' economic responsibilities and party system configuration. This allows us to take advantage of the subnational comparative method (Snyder 2001): by focusing on subnational cases within a single country, we control for factors such as the regions' government institutions or the characteristics of the national political system to a far greater extent than is possible in studies that compare units within different federations.

The process of decentralization in Spain established seventeen regions with their own democratically-elected institutions. Four of these regions were granted the maximumlevel of self-government allowed by the Spanish constitution at the outset (the so-called fast-track regions), whereas the other thirteen had to wait for five years before being able to increase their powers (Colomer 1998). Yet, the evolution of the decentralization process has equalized the responsibilities attributed to these two types of regions to such an extent that few differences exist in terms of regional policy responsibilities across regions (Aja 2014). However, revenue powers constitute an important difference; whereas the central government levies and collects most taxes in the 15 regions financed under the "common regime" - and later redistributes the revenues among these regions with the aim of producing fiscal equalization - the Basque provinces and Navarre enjoy fiscal autonomy, so they possess their own treasuries, they are fully responsible for most of the taxes, and enjoy more flexibility to lower or raise the rates of income or corporate tax (Bosch and Duran 2008). The central government is, therefore, the main responsible for fiscal policy in all regions with the exception of the Basque Country and Navarre.

Yet, the major source of differences between regions is the strength of regional identities and the distinctiveness of their party systems. In some regions, regional identities are linked to alternative national projects, championed by nationalist parties, whereas in other regions distinctive territorial identities are less spread and unconnected with nationhood claims (Moreno et al. 1998). As a result, regional party systems differ 
in varying degrees from the national party system. In most of the regions, the electoral competition is dominated by Spanish-wide parties, so the regional government is held by either the incumbent or the main opposition party in central government institutions. By contrast, in other regions and, particularly, in the Basque Country and Catalonia, the regional incumbent (or the main opposition party) is usually a region-specific nationalist party that stands for the promotion of the region's interests (Pallarés and Keating 2003).

\section{Data}

This study employs two sources of data. First, we draw on an online survey experiment conducted in October of 2013 on a Spanish-wide sample of internet users $(\mathrm{N}=843){ }^{2}$ The experiment allows us to ascertain the extent to which citizens bring their responsibility judgments in line with their partisan and regional attachments when exposed to varying information about their region's economic performance, and how those adjustments are moderated by the regional partisan context. The study was designed to address the concerns over reverse causality that often arise when examining observational data, and specifically to control for the possibility that voters are biasing their perceptions of the economy according to prior identities and responsibility judgments (Tilley and Hobolt 2011).

Our second source of data comes from a survey study administered face-to-face to five regionally representative samples between October 2007 and March 2008. ${ }^{3}$ The regions were selected to capture regional diversity regarding the prevalence of distinctive

\footnotetext{
${ }^{2}$ The experiment was embedded in a wave of an online panel survey of the Spanish population. Due to Internet use sharply decreasing with age, the original sample is restricted to young and middle aged adults (respondents' age ranges between 18 and 48 years in our sample). Quotas were applied for sex, age, education, and region, thus enabling to examine how different regional partisan contexts moderate the degree of bias in responsibility judgements. Respondents from the Canary Islands and Navarre are excluded from the analysis as the questionnaire did not include a measure of proximity to these regions' incumbents (Coalición Canaria and Unión del Pueblo Navarro, respectively).

${ }^{3}$ The data were collected by the Centro de Investigaciones Sociológicas (study no. 2734). Regional sample sizes range between 1,490 and 2,400.
} 
territorial identities and regional party system configurations. Regional identities are predominantly strongest in the Basque Country and Catalonia, which also contain the most idiosyncratic party systems - each with at least two relevant nationalist parties, one of them consistently among the top two in either regional or national elections. Nationalism is pervasive but less widespread in Galicia, where the Bloque Nacionalista Gallego gets representation in the regional chamber but rarely challenges the main national parties. In Andalusia, although distinctive feelings of regional attachments are non-negligible, region-wide formations have only attained minor and sporadic success. Finally, region-specific parties are irrelevant in Castilla y León, where regional identity is systematically shared with the Spanish identity.

Combining the survey experiment with regional surveys greatly improves the external validity of our results. The use of regionally representative, face-to-face surveys allows us to obtain fine-grained, region-by-region descriptive evidence of differences in responsibility attributions when respondents in a real-world situation are not explicitly given an economic treatment. Furthermore, the fact that the experimental and the observational studies were drawn at different points in time allows us to test if the same pattern of attribution bias emerges under very different political and economic contexts.

On the one hand, the two studies were collected under different partisan configurations. By late 2007, when the five-region study was conducted, the Socialist party (PSOE) led a minority government, to be reissued in 2008; in 2013, when the experiment was carried out, it was the conservatives (PP) who were in office at the national level, after attaining a majority in the 2011 snap election. As shown in Table 1, some regions also underwent government change following their respective regional elections, mostly at the expense of the Socialists. As a result, two of the regions under in-party governments in the 2007 study (Andalucía and Catalonia) featured an out-party government in 2013, while the other (Galicia) remained in-party as the Socialists lost the regional government to the PP. Castilla y León, which featured an out-party government in 2007, 
became an in-party region after the conservatives won the national government, while the Basque Country remained under the out-party government of the Basque nationalists. Finally, the Catalan government, led by the Socialists in 2007, was back in the hands of the nationalists at the time of our experiment.

[Table 1]

Additionally, our studies differ markedly as to the economic situation of the country at the time of data collection. By the end of 2007, the Spanish economy had just started to show signs of deterioration after a long period of buoyance boosted by the housing bubble; by 2013, the country was still undergoing the second wave of the deepest recession in decades, and the banking system had only recently been bailed out. Yet, the economy was certainly showing some signs of recovery. The national GDP grew in the third quarter of 2013 for the first time in more than two years; unemployment, while reaching a historic peak of 26.9 per cent in the first quarter, started to recede subsequently for the first time in five years. Therefore, the data used in this paper covers a diverse range of time-varying political contexts and distinct economic circumstances, which significantly enhances the external validity of the results.

\section{Results}

\section{The Survey Experiment}

As sketched above, our experiment's main goal was to establish the causal status of performance evaluations and voters' attachments in biasing the formation of responsibility judgments between levels of government. To ascertain the extent of attribution bias, we examined the effect of exposing citizens to information about regional economic performance on their attributions of responsibility. We used a between-subjects, one-shot design where respondents were randomly assigned to one of 
three conditions with varying information about the recent evolution of the economic situation in the respondent's region of residence. In the positive information condition, respondents were told: "Some of the more recent data show signs of improvement in the state of the economy in [region] during the last quarter." In the negative information condition, the same wording was used but the term "improvement" was replaced by "downturn." Respondents assigned to the control condition were not presented any information about the evolution of the regional economy. Next, all respondents were asked two questions: "To what extent do you think the regional government is responsible for the state of the economy in [region]?" and "To what extent do you think the national government is responsible for the state of the economy in [region]?"

The dependent variable in our models is the net regional attribution, that is, the difference between the regional government attribution score and the national government attribution score-an operationalization that has been argued to more accurately capture the attribution of responsibility in multilevel systems (Hobolt and Tilley 2014; see also Rudolph 2016). This net regional score theoretically ranges from -10 to +10 , where -10 means that the national government is assigned all the responsibility and +10 indicates the regional government is fully responsible.

In order to test for partisan bias in responsibility judgments, the net regional attribution is regressed on the interaction between economic information (our treatment) and the individual's partisanship. This interaction ascertains how partisan groups differently adjust their responsibility attributions to information about how the economy is doing. Of key interest to our analysis, however, is the three-way interaction between economic information, voters' partisanship, and the partisanship of the regional government, as it tests the extent to which partisan bias varies across regions as a function of the in-party or out-party condition of the regional incumbent. Two dummy variables are used to identify the positive and the negative information conditions, the control group serving as the baseline category. Partisanship is captured by a question measuring how close 
respondents feel to the leading incumbent party, on a 5-point scale recoded to run from 0 (most distant) to 1 (closest). Finally, a dummy variable identifies regions with an outparty regional incumbent relative to regions with an in-party incumbent, as reported in Table 1.

[Table 2]

Table 2 contains the results of the OLS model. Following Hypothesis 1, we expect partisan bias to be confined to regions where a party other than the national incumbent is in office. In order to allow for partisan bias to vary by the partisanship of the regional government, our model includes a three-way interaction between each of the treatments, respondents' proximity to the regional incumbent, and region type, along with all of their constituent terms. The joint-hypothesis $F$-test of the coefficients in the three-way interaction is statistically significant $(p<0.01)$, indicating that the extent to which attributions are shaped by a combination of performance evaluations and feeling towards the incumbent is dependent on the partisanship of the regional incumbent. Indeed, the estimates imply that there is no attribution bias in regions with an in-party regional incumbent (the joint-hypothesis test of the treatment $\times$ proximity interaction is not statistically significant, $p>0.1$ ), whereas they provide strong evidence of bias in regions with an out-party incumbent $(p<0.01)$.

Given the intricacies involved in the interpretation of multiple interaction models, Figure 1 provides an illustration of the estimated effects. The first panel shows that, in regions with an in-party incumbent, the predicted attribution scores remain basically the same across conditions for both those feeling very close to the incumbent ( 1 on the $0-1$ proximity scale) and those feeling very distant (0). Yet, as shown in the second panel, stark differences are visible in out-party regions. For someone feeling very close to the incumbent, the model predicts a score of -2.6 on the -10 to +10 attribution scale when confronted with bad news about the regional economy, meaning that substantially more 
responsibility is ascribed to the national government than is to the regional government. When faced with good news, the same individual is predicted a score of 1.8 , which entails that the regional government is held more responsible than the national government. By contrast, those that feel very distant from the incumbent seem largely unaffected by the valence of the information given, according to the model. It is important to note, however, that such individuals score significantly higher than government supporters on the regional attribution scale when exposed to negative performance information, and significantly lower when exposed to positive information. $^{4}$

\section{[Figure 1]}

We next examined Hypothesis 2, according to which the rationalization of attributions on the basis of territorial identity would be conditional of the regional government being led by a nationalist party. To operationalize individuals' territorial identity, we use a forced-choice question asking respondents whether they feel "Only Spanish", "More Spanish than from the region", "As much Spanish as from the region", "More from the region than Spanish", or "Only from the region", which was recoded to run from 0 to 1. A dummy variable identifies regions under a nationalist incumbent (i.e., Catalonia and the Basque Country). The results are displayed in Table 3.

\section{[Table 3]}

The estimates confirm that rationalizations driven by territorial identity vary significantly by region (the coefficients in the three-way interaction are jointly significant at $p<0.05)$. As illustrated in Figure 2, respondents at both ends of the

\footnotetext{
${ }^{4}$ We replicated the analysis using respondents' proximity to the national incumbent instead of their proximity to the regional incumbent. The results, presented in section A of the Supplemental Appendix, show a pattern similar to that found in the present analysis, such that closeness to the PP consistently moderates the adjustment of responsibility attributions to the valence of information in regions with an out-party incumbent, but not in regions with an in-party incumbent.
} 
identity scale in regions under a non-nationalist incumbent are hardly distinguishable in their responsibility attributions and these appear to be unaffected by information on the situation of the regional economy (the treatment $\times$ identity interaction is not statistically significant, $p>0.1$ ). In contrast, respondents in regions with a nationalist incumbent responded differently to the treatments based on their prior territorial attachments $(p<0.01)$. As shown in the rightmost panel, the attribution of responsibility to the regional government vis-à-vis the national government increases by 4.1 points in average among individuals feeling attached only to the region when exposed to positive information about the regional economy, as compared to when faced with negative information, while it decreased by 1.4 points among those reporting an exclusive Spanish identity. The analysis of variations by territorial identity thus lends support to Hypothesis 2.

[Figure 2]

The findings thus provide strong evidence in support of the idea that rationalizations by virtue of partisan and territorial identities are activated in contexts where the combination of government arrangements at the national and regional levels promotes the confrontation along those same alignments. As expected, the partisan bias of responsibility judgments is restricted to regions where the regional incumbent is from another party than the national incumbent, while attribution bias driven by territorial attachments is only visible in regions where the government is led by a nationalist party. ${ }^{5}$

Our results also suggest that the information provided in the negative treatment, for the most part, matched the existing, heavily pessimistic impressions of the Spanish citizens at the time of the study, and hence failed to motivate a change in their attributions of

\footnotetext{
${ }^{5}$ These results are robust to alternative specifications of the proximity and identity variables, as shown in section B of the Supplemental Appendix.
} 
responsibility. Indeed, responsibility judgments of those exposed to negative information about the regional situation do not significantly depart from those in the control group. It is worth noting, however, that attribution scores within both the control and negative information groups differ markedly by partisan and territorial identifications in regions with an out-party incumbent and with a nationalist government, respectively. The contrast is particularly pronounced in connection to territorial attachment: respondents with predominantly Spanish feelings tend to disproportionately ascribe responsibility for the region's economy to the regional government, while respondents with predominantly regional feelings disproportionately blame the national government. This pattern of differences points to the existence of pretreatment effects: participants in our experiment had already been exposed to (overwhelmingly dull) "real-world" economic evidence and news and adjusted their responsibility attributions accordingly, based on their group identifications (Gaines et al. 2007). That systematic differences within the negative treatment and control groups only emerge in regions with out-party or nationalist governments, but not in those free of cross-government divergence, attests to rationalization processes in line with the posited hypotheses. It is to the systematic analysis of the effects of such "real-world" conditions that we turn to in the next section.

\section{The Five-Region Study}

As we sketched above, the five regions sampled in this study were selected to represent the myriad of social, political, and historical circumstances occurring in the Spanish "state of autonomies." The five-region survey provides a perfect mix of regionally representative samples to test our hypotheses about the moderating role of partisan contexts in the group-serving rationalization of attributions. Andalusia, Catalonia, and Galicia featured in-party (and consequently non-nationalist) governments; accordingly, we would not expect attributions of responsibility to be biased on the basis of neither 
partisan nor territorial affinities. Castilla y León featured an out-party, non-nationalist government, hence we would expect attributions to be biased on the basis of partisanship but not territorial identity. Finally, the Basque Country featured a nationalist (and consequently out-party) government, so we would expect attributions to be biased on the basis of both partisan and territorial identities.

Given that sample sizes are large enough to be representative at the regional level, the same model is estimated separately for each of the five regions. Sample size also allows the two posited bias mechanisms to be estimated concomitantly. Hence respondents' attributions of responsibility are regressed on the reported regional economic performance and the interaction of this with government support on the one hand, and with territorial identity on the other.

To measure the attribution of responsibilities, we use two questions asking respondents how much the national and the regional governments has each influenced the recent evolution of the region's economy, as reported on a 4-point scale ranging from "not at all" to "a great deal". Our dependent variable is the difference between the influence ascribed to the regional government and the influence ascribed to the national government. The resulting net regional attribution score is coded to run from -1 to 1 , where -1 means that the national government is assigned all the responsibility and 1 means that the regional government is fully responsible. Regional economic performance is operationalized using respondents' retrospective assessment of the region's economy, measured on a 5-point scale from "much worse" to "much better". Following Hobolt et al. (2013), incumbent support is captured using an 11-point evaluation of the regional government's record. To measure territorial identity, we again employ the 5-point scale ranging from "only Spanish" to "only from the region". Finally, the models include controls for respondents' sex, age, educational attainment, 
and political knowledge. ${ }^{6}$ All independent variables (but age) are coded to range from 0 to 1 . Table 4 shows the regression estimates for each of the five regions.

\section{[Table 4]}

The results are largely consistent with the posited hypotheses. In line with Hypothesis 1, the interaction between impressions of the economy and government evaluation is not statistically significant in regions with an in-party incumbent, which indicates that citizens are not adjusting their responsibility judgments according to their ingroup identities. Based on the estimates in Table 4, Figure 3 compares the relationship between net regional attributions and assessments of economic performance among government supporters (those giving it the highest rating) to that among opponents (lowest), while setting all other variables at their observed values. The figure clearly illustrates that in Andalusia, Catalonia, and Galicia differences in the slopes of economic performance between the two groups are negligible. Conversely, we find evidence of partisan bias in the out-party regions of Castilla y León and, to a lesser extent, the Basque Country. The interaction between economic performance and government evaluation is highly significant in the former case: as shown in the corresponding panel of Figure 3, the likelihood of attributing responsibility for the economy to the regional government vis-à-vis the national government among supporters of the Castilian incumbent increases as economic assessments become more positive, while exactly the reverse is true among the incumbents' opponents.

Differences are much less pronounced (albeit significant at the $p<0.1$ level) in the Basque country, where only the most enthusiastic supporters of the regional government appear to slightly adjust their responsibility attributions according to their perceptions of the economy.

\footnotetext{
${ }^{6}$ Education is measured using a 4-level variable: Primary or less, lower secondary, higher secondary, university. Political knowledge is an additive index based on six factual items.
} 
Finally, the results in Table 4 show that only in the Basque Country is the interaction between economic performance and territorial identity statistically significant, indicating that, as predicted by Hypothesis 2, rationalization driven by territorial attachment is confined to regions with nationalist governments. As shown in Figure 4, voters feeling only Basque are more likely to assign the responsibility for the region's economy to the regional government the more positive their assessment of the region's economic situation, whereas voters feeling only Spanish tend to give more credit to the national government as their perception of the region's economic situation improves. In regions with non-nationalist incumbents, however, territorial identity does not appear to meaningfully shape attributions of responsibility. It is worth noting that territorial identity makes no difference even in Catalonia, in spite of widespread feelings of regional attachment and a deeply ingrained history of nationalist mobilization — or in Galicia or even Andalusia, both also with remarkable regionalist records. Just as partisan bias apparently requires the partisan confrontation across governments to be activated, territorial bias does not seem to occur unless a regional incumbent plays the territorial card against the national government. ${ }^{7}$

\section{Discussion}

This study has provided strong evidence in support of the hypothesis that the vertical division of power facilitates group-based attribution bias in contexts where different parties rule over different levels of government, but not in contexts where the regional

\footnotetext{
${ }^{7}$ In order to subject our hypotheses to a more formal test and to allow a clearer comparison with the analysis of the experiment, we also estimated a series of general models pooling all regions together and including interactions between perceptions of the economy, government support/territorial identity, and dummy variables identifying regions with out-party/nationalist incumbents. The estimates, shown in section D of the Supplemental Appendix, consistently indicate that the three-way interactions are statistically significant $(\mathrm{p}<0.01)$ and the effects are in the expected direction, suggesting that attribution bias is dependent on the region's partisan context.
} 
incumbent belongs to the same party as the national incumbent. Our experiment reveals partisan motivated reasoning in action: even if the treatments did not directly prime directional goals, when offered the opportunity to counter-argue a valenced assessment of the regional economy, voters in out-party regions systematically adjusted their responsibility judgments to reach a conclusion that is more in line with their group attachments. By contrast, the attributions of voters under in-party regional governments are not consistently affected by information about the economy. The analysis of the observational data further validates the key role of partisan conflict in activating directional motives.

Our findings have likely important implications for research on the prevalence of economic voting across institutional contexts. Starting with Powell and Whitten (1993), scholars have shown that the dispersion of power blurs the lines of responsibility, eroding the citizens' ability to allocate credit and blame and ultimately hindering the extent to which governments are held to account for policy outcomes. The implied assumption is often that an accurate allocation of responsibility under conditions of divided power is more cognitively demanding, i.e. requires more effort and information from voters (e.g., Cutler 2004; Gomez and Wilson 2008). The evidence provided in this paper helps identify attribution bias as an additional mechanism by which low clarity of responsibility may hinder debilitate retrospective voting. To the degree that voters are allowed to allocate the responsibility to different parties, divided government creates incentives for them to engage in credit taking and blame shifting on the basis of their predispositions, which in turn weakens the relationship between economic conditions and government support.

This reasoning is consistent with a number of works showing that the strength of performance voting is reduced when power is shared among different parties: in cases of "divided government," where the ruling party in the executive does not control a majority of seats in the legislature (Leyden and Borrelli 1995; Lowry et al. 1998); under 
conditions of partisan "cohabitation" in semi-presidential systems (Lewis-Beck and Nadeau 2000); and in subnational elections not involving incumbents of the national executive's party (Atkeson and Partin 1995; León and Orriols 2016; Stein 1990). It also conforms to Hobolt et al.'s (2013) finding that it is the partisan cohesion of government, rather than the institutional concentration of power, that moderates the impact of performance evaluations on incumbent support. All of these examples suggest that variations in the partisan distribution of power moderate retrospective voting under equivalent institutional arrangements. The role of institutional arrangements cannot be fully understood aside from the partisan context and its influence on the likelihood of attribution bias. Further research should be aimed at disentangling the relative contribution of attribution bias vis-à-vis cognitive complexity in explaining the conditioning effect of institutions on performance voting.

Our study has also addressed the largely unexplored role of territorial identities in shaping responsibility judgments in federations. It has been demonstrated that such feelings of attachment may indeed bias attributions in a similar way than partisanship. However, the mere presence of alternative national identities, as is the case of Catalonia and the Basque Country, does not appear to automatically translate into the adjustment of attributions in favor of a particular level of government. Rather, the results in this paper indicate that substantial rationalizations driven by territorial attachments only occur when regional governments are controlled by nationalist parties. Under such circumstances, voters with strong feelings of regional (national) identification will tend to claim successes for the regional (national) government, holding constant their partisan allegiances.

Further research will be needed to examine how territorial identities affect responsibility judgments in other contexts and to validate the role of partisan competition in channeling their influence. We would in principle expect a pattern similar to that found here in other multilevel democracies with strong regional attachments, such as Belgium, 
Canada, or the United Kingdom. Given its peculiar organization of government and the lack of a comparable party system, much is to be learned yet about the role of incumbency and territorial identities in shaping responsibility attributions in the context of the European Union-particularly in view of the growing success of parties with a strong nationalist agenda across the continent.

\section{References}

Aja, E. (2014). Estado autonómico y reforma federal. Madrid: Alianza.

Anderson, C. D. (2006). Economic Voting and Multilevel Governance: A Comparative Individual-Level Analysis. American Journal of Political Science, 50(2), 449463.

Anderson, C. J. (2000). Economic voting and political context: a comparative perspective. Electoral Studies, 19(2-3), 151-170.

Arceneaux, K. (2006). The Federal Face of Voting: Are Elected Officials Held Accountable for the Functions Relevant to Their Office? Political Psychology, 27(5), 731-754.

Atkeson, L. R., \& Partin, R. W. (1995). Economic and Referendum Voting: A Comparison of Gubernatorial and Senatorial Elections. American Political Science Review, 89(1), 99-107.

Bisgaard, M. (2015). Bias Will Find a Way: Economic Perceptions, Attributions of Blame, and Partisan-Motivated Reasoning during Crisis. Journal of Politics, $77(3), 849-860$.

Bosch, N., \& Duran, J. M. (Eds.). (2008). Fiscal Federalism and Political Decentralization: Lessons from Spain, Germany and Canada. Cheltenham: Elgar.

Brown, A. R. (2010). Are Governors Responsible for the State Economy? Partisanship, Blame, and Divided Federalism. Journal of Politics, 72(03), 605-615.

Campbell, A., Converse, P. E., Miller, W. E., \& Stokes, D. E. (1960). The American Voter. New York: John Wiley \& Sons. 
Chernyha, L. T., \& Burg, S. L. (2012). Accounting for the effects of identity on political behavior: Descent, strength of attachment, and preferences in the regions of Spain. Comparative Political Studies, 45(6), 774-803.

Colomer, J. M. (1998). The Spanish "state of autonomies": Non-institutional federalism. West European Politics, 21(4), 40-52.

Cramer, K. J. (2016). The politics of resentment: rural consciousness in Wisconsin and the rise of Scott Walker. Chicago: University of Chicago Press.

Cutler, F. (2004). Government Responsibility and Electoral Accountability in Federations. Publius: The Journal of Federalism, 34(2), 19-38.

Cutler, F. (2008). Whodunnit? Voters and Responsibility in Canadian Federalism. Canadian Journal of Political Science, 41(3), 627-654.

Downs, W. M. (1999). Accountability Payoffs in Federal Systems? Competing Logics and Evidence from Europe's Newest Federation. Publius: The Journal of Federalism, 29(1), 87-110.

Druckman, J. N., Peterson, E., \& Slothuus, R. (2013). How Elite Partisan Polarization Affects Public Opinion Formation. American Political Science Review, 107(1), $57-79$.

Fiske, S. T., \& Taylor, S. E. (1991). Social cognition (2nd ed.). New York: McGrawHill.

Fitjar, R. D. (2010). Explaining variation in sub-state regional identities in Western Europe. European Journal of Political Research, 49(4), 522-544.

Gaines, B. J., Kuklinski, J. H., \& Quirk, P. J. (2007). The Logic of the Survey Experiment Reexamined. Political Analysis, 15(1), 1-20.

Gomez, B. T., \& Wilson, J. M. (2001). Political Sophistication and Economic Voting in the American Electorate: A Theory of Heterogeneous Attribution. American Journal of Political Science, 45(4), 899-914.

Gomez, B. T., \& Wilson, J. M. (2003). Causal Attribution and Economic Voting in American Congressional Elections. Political Research Quarterly, 56(3), 271282.

Gomez, B. T., \& Wilson, J. M. (2008). Political Sophistication and Attributions of Blame in the Wake of Hurricane Katrina. Publius: The Journal of Federalism, 38(4), 633-650.

Hepburn, E. (2009). Introduction: Re-conceptualizing Sub-state Mobilization. Regional \& Federal Studies, 19(4-5), 477-499. 
Hobolt, S. B., \& Tilley, J. (2014). Who's in Charge? How Voters Attribute Responsibility in the European Union. Comparative Political Studies, 47(6), 795-819.

Hobolt, S. B., Tilley, J., \& Banducci, S. (2013). Clarity of responsibility: How government cohesion conditions performance voting. European Journal of Political Research, 52(2), 164-187.

Hobolt, S. B., Tilley, J., \& Wittrock, J. (2013). Listening to the Government: How Information Shapes Responsibility Attributions. Political Behavior, 35(1), 153174.

Johns, R. (2011). Credit Where it's Due? Valence Politics, Attributions of Responsibility, and Multi-Level Elections. Political Behavior, 33(1), 53-77.

Key, V. O. J. (1966). The Responsible Electorate: Rationality in Presidential Voting, 1936-1960. Cambridge: Harvard University Press.

Kunda, Z. (1990). The case for motivated reasoning. Psychological Bulletin, 108(3), $480-498$.

León, S. (2011). Who is responsible for what? Clarity of responsibilities in multilevel states: The case of Spain. European Journal of Political Research, 50(1), 80109.

León, S., \& Orriols, L. (2016). Asymmetric federalism and economic voting. European Journal of Political Research, 55(4), 847-865.

Lewis-Beck, M. S., \& Nadeau, R. (2000). French electoral institutions and the economic vote. Electoral Studies, 19(2-3), 171-182.

Leyden, K. M., \& Borrelli, S. A. (1995). The Effect of State Economic Conditions on Gubernatorial Elections: Does Unified Government Make a Difference? Political Research Quarterly, 48(2), 275-290.

Lowry, R. C., Alt, J. E., \& Ferree, K. E. (1998). Fiscal Policy Outcomes and Electoral Accountability in American States. American Political Science Review, 92(04), 759-774.

Malhotra, N. (2008). Partisan Polarization and Blame Attribution in a Federal System: The Case of Hurricane Katrina. Publius: The Journal of Federalism, 38(4), 651670.

Malhotra, N., \& Kuo, A. G. (2008). Attributing Blame: The Public's Response to Hurricane Katrina. Journal of Politics, 70(1), 120-135. 
Marsh, M., \& Tilley, J. (2010). The Attribution of Credit and Blame to Governments and Its Impact on Vote Choice. British Journal of Political Science, 40(01), $115-134$.

Moreno, L., Arriba, A., \& Serrano, A. (1998). Multiple identities in decentralized Spain: The case of Catalonia. Regional \& Federal Studies, 8(3), 65-88.

Nawara, S. P. (2015). Who Is Responsible, the Incumbent or the Former President? Motivated Reasoning in Responsibility Attributions. Presidential Studies Quarterly, 45(1), 110-131.

Pallarés, F., \& Keating, M. (2003). Multi-Level Electoral Competition: Regional Elections and Party Systems in Spain. European Urban and Regional Studies, 10(3), 239-255.

Parker-Stephen, E. (2013). Clarity of responsibility and economic evaluations. Electoral Studies, 32(3), 506-511.

Peffley, M., \& Williams, J. T. (1985). Attributing Presidential Responsibility for National Economic Problems. American Politics Quarterly, 13(4), 393-425.

Powell, G. B. (2000). Elections as Instruments of Democracy: Majoritarian and Proportional Visions. New Haven: Yale University Press.

Powell, G. B., \& Whitten, G. D. (1993). A Cross-National Analysis of Economic Voting: Taking Account of the Political Context. American Journal of Political Science, 37(2), 391-414.

Rodden, J. (2004). Comparative Federalism and Decentralization: On Meaning and Measurement. Comparative Politics, 36(4), 481-500.

Rudolph, T. J. (2003a). Institutional Context and the Assignment of Political Responsibility. Journal of Politics, 65(1), 190-215.

Rudolph, T. J. (2003b). Who's Responsible for the Economy? The Formation and Consequences of Responsibility Attributions. American Journal of Political Science, 47(4), 698-713.

Rudolph, T. J. (2006). Triangulating Political Responsibility: The Motivated Formation of Responsibility Judgments. Political Psychology, 27(1), 99-122.

Rudolph, T. J. (2016). The Meaning and Measurement of Responsibility Attributions. American Politics Research, 44(1), 106-130.

Sirin, C. V., \& Villalobos, J. D. (2011). Where Does the Buck Stop? Applying Attribution Theory to Examine Public Appraisals of the President. Presidential Studies Quarterly, 41(2), 334-357. 
Snyder, R. (2001). Scaling Down: The Subnational Comparative Method. Studies in Comparative International Development, 36(1), 93-110.

Stein, R. M. (1990). Economic voting for governor and US senator: The electoral consequences of federalism. Journal of Politics, 52(01), 29-53.

Taber, C. S., \& Lodge, M. (2006). Motivated Skepticism in the Evaluation of Political Beliefs. American Journal of Political Science, 50(3), 755-769.

Tajfel, H., \& Turner, J. (1979). An integrative theory of intergroup conflict. In W. G. Austin \& S. Worchel (Eds.), The social psychology of intergroup relations (pp. 33-47). Monterey, CA: Brooks-Cole.

Taylor, D. M., \& Doria, J. R. (1981). Self-Serving and Group-Serving Bias in Attribution. Journal of Social Psychology, 113(2), 201-211.

Tilley, J., \& Hobolt, S. B. (2011). Is the Government to Blame? An Experimental Test of How Partisanship Shapes Perceptions of Performance and Responsibility. Journal of Politics, 73(2), 316-330.

Whitten, G. D., \& Palmer, H. D. (1999). Cross-national analyses of economic voting. Electoral Studies, 18(1), 49-67. 
Table 1 Party of the head of the incumbent government in the regions covered in the studies

\begin{tabular}{lcc}
\hline & $\begin{array}{c}\text { Survey experiment } \\
(2013)\end{array}$ & $\begin{array}{c}\text { Five-region study } \\
(2007-08)\end{array}$ \\
\hline National government & $\mathrm{PP}$ & PSOE \\
Regional governments & & \\
Andalusia & $\mathrm{PSOE}^{\dagger}$ & $\mathrm{PSOE}^{\dagger}$ \\
Aragón & $\mathrm{PP}^{\dagger}$ & \\
Asturias & $\mathrm{PSOE}^{\dagger}$ & \\
Cantabria & $\mathrm{PP}$ & $\mathrm{PP}^{\dagger}$ \\
Castilla y León & $\mathrm{PP}$ & \\
Castilla-La Mancha & $\mathrm{PP}$ & $\mathrm{PSC}^{\dagger}$ \\
Catalonia & $\mathrm{CiU}$ & \\
Comunitat Valenciana & $\mathrm{PP}$ & $\mathrm{PSOE}^{\dagger}$ \\
Extremadura & $\mathrm{PP}$ & \\
Galicia & $\mathrm{PP}$ & \\
Balearic Islands & $\mathrm{PP}$ & \\
La Rioja & $\mathrm{PP}$ & $\mathrm{PNV}^{\ddagger}$ \\
Madrid & $\mathrm{PP}$ & \\
Murcia & $\mathrm{PP}$ & \\
Basque Country & $\mathrm{PNV}$ & \\
\hline
\end{tabular}

${ }^{\dagger}$ Non-nationalist out-party incumbents; ${ }^{\ddagger}$ Nationalist out-party incumbents. Although formally a separate party, the Catalan PSC is a federal partner with the PSOE. 
Table 2 The role of proximity to regional incumbent in attributions of responsibility, 2013

\begin{tabular}{lc}
\hline Treatment (ref.=Control): & \\
Negative & -0.11 \\
& $(0.38)$ \\
Positive & -0.08 \\
& $(0.37)$ \\
Proximity to regional incumbent & 0.29 \\
& $(0.69)$ \\
Out-party incumbent & 0.27 \\
& $(0.48)$ \\
Negative $\times$ Proximity & -0.06 \\
& $(0.97)$ \\
Positive $\times$ Proximity & -0.64 \\
& $(1.04)$ \\
Negative $\times$ Out-party & 0.53 \\
& $(0.64)$ \\
Positive $\times$ Out-party & 0.04 \\
Out-party $\times$ Proximity & $(0.69)$ \\
& $-2.48 *$ \\
Negative $\times$ Proximity $\times$ Out-party & $(1.10)$ \\
& -1.18 \\
Positive $\times$ Proximity $\times$ Out-party & $(1.48)$ \\
Constant & $4.21 * *$ \\
R-squared & $(1.61)$ \\
Observations & 0.18 \\
& $(0.27)$ \\
Ondan & 0.06 \\
& 812 \\
\hline
\end{tabular}

Unstandardized OLS coefficients with standard errors in parentheses.

$+\mathrm{p}<0.1, * \mathrm{p}<0.05, * * \mathrm{p}<0.01$ 
Table 3 The role of territorial identity in attributions of responsibility, 2013

$\begin{array}{lc}\text { Treatment (ref.=Control): } & \\ \text { Negative } & -0.71 \\ & (0.52) \\ \text { Positive } & -0.50 \\ & (0.54) \\ \text { Identity } & -1.10 \\ & (0.77) \\ \text { Nationalist incumbent } & 3.12^{* *} \\ & (0.95) \\ \text { Negative } \times \text { Identity } & 1.70 \\ & (1.04) \\ \text { Positive } \times \text { Identity } & 1.10 \\ & (1.07) \\ \text { Negative } \times \text { Nationalist } & 0.33 \\ & (1.27) \\ \text { Positive } \times \text { Nationalist } & -1.32 \\ & (1.38) \\ \text { Nationalist } \times \text { Identity } & -6.05^{* *} \\ \text { Negative } \times \text { Identity } \times \text { Nationalist } & (1.54) \\ \text { Positive } \times \text { Identity } \times \text { Nationalist } & -1.55 \\ \text { Constant } & (2.04) \\ \text { R-squared } & 4.63^{*} \\ \text { Observations } & (2.33) \\ & 0.68+ \\ & \end{array}$

Unstandardized OLS coefficients with standard errors in parentheses.

$+\mathrm{p}<0.1, * \mathrm{p}<0.05, * * \mathrm{p}<0.01$ 
Table 4 The role of partisan and territorial attachments in attributions of responsibility in five regions, 2007-8

\begin{tabular}{lccccc}
\hline & & Castilla y & & & Basque \\
& Andalusia & León & Catalonia & Galicia & \begin{tabular}{c} 
Country \\
\hline Economic performance
\end{tabular} \\
& 0.01 & $-0.67^{* *}$ & 0.04 & 0.03 & $-0.43^{* *}$ \\
Government support & $(0.07)$ & $(0.11)$ & $(0.09)$ & $(0.07)$ & $(0.13)$ \\
& -0.01 & $-0.98^{* *}$ & -0.00 & -0.01 & $-0.27^{*}$ \\
Territorial identity & $(0.04)$ & $(0.09)$ & $(0.05)$ & $(0.05)$ & $(0.11)$ \\
& -0.05 & -0.10 & -0.03 & 0.08 & $-0.23^{*}$ \\
Economy $\times$ Support & $(0.06)$ & $(0.10)$ & $(0.04)$ & $(0.06)$ & $(0.10)$ \\
& -0.04 & $1.76^{* *}$ & 0.10 & 0.11 & $0.32+$ \\
Economy $\times$ Territorial id & $(0.08)$ & $(0.18)$ & $(0.14)$ & $(0.09)$ & $(0.20)$ \\
& 0.16 & 0.04 & -0.02 & -0.05 & $0.69^{* *}$ \\
R-squared & $(0.11)$ & $(0.18)$ & $(0.10)$ & $(0.10)$ & $(0.17)$ \\
Observations & 0.02 & 0.12 & 0.02 & 0.02 & 0.08 \\
\hline
\end{tabular}

Unstandardized regression coefficients with standard errors in parentheses. Constant and controls for sex, age, education, and political knowledge not shown.

$+\mathrm{p}<0.1, * \mathrm{p}<0.05, * * \mathrm{p}<0.01$ 
Fig. 1 Responsibility attributions by experimental condition, proximity to regional incumbent, and partisan context

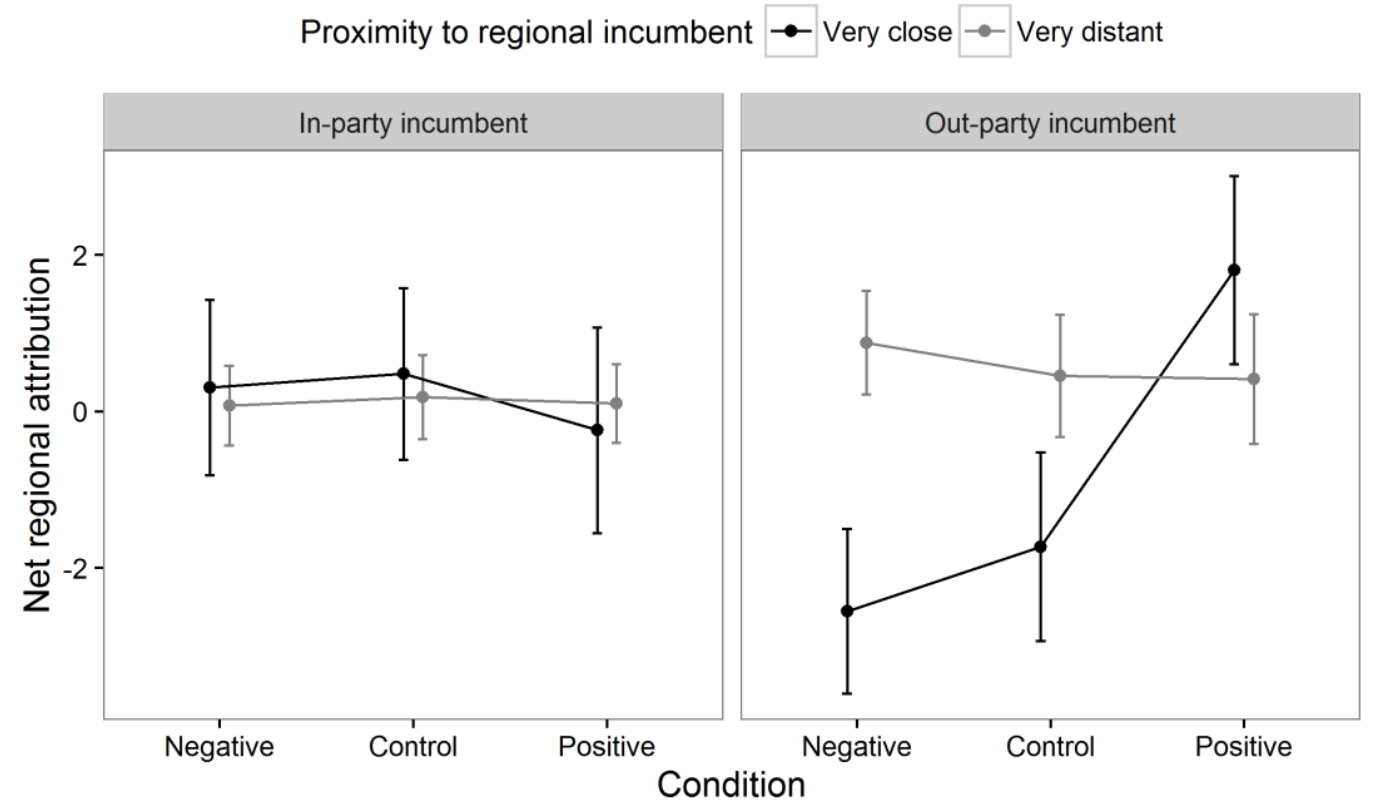

Note: predicted values and 95\% confidence intervals based on the estimates in Table 2.

Fig. 2 Responsibility attributions by experimental condition, territorial identity, and partisan context

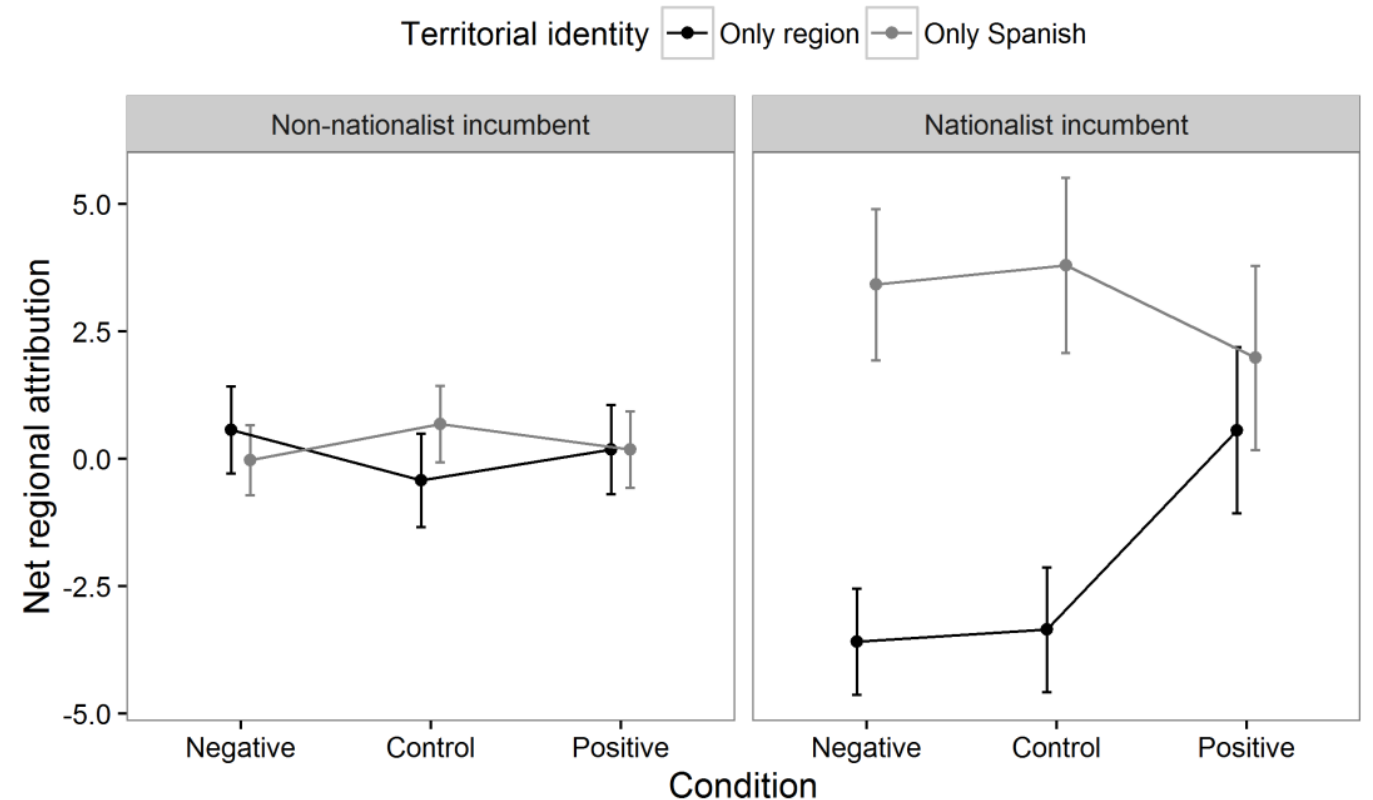

Note: predicted values and $95 \%$ confidence intervals based on the estimates in Table 3 . 
Fig. 3 Responsibility attributions by evaluation of the regional economy and government support in five regions

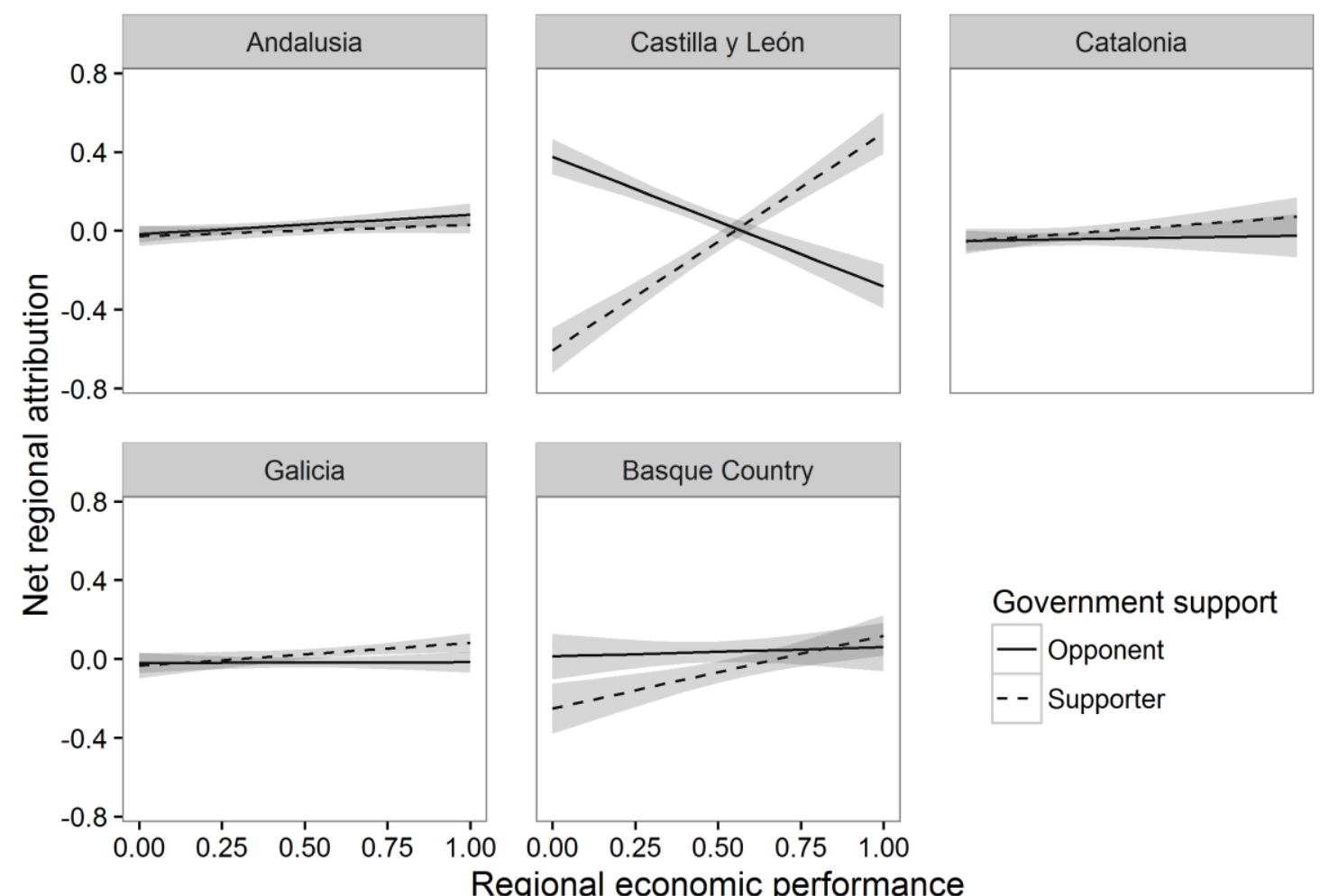

Note: predicted values and 95\% confidence intervals based on the estimates in Table 4. 
Fig. 4 Responsibility attributions by evaluation of the regional economy and territorial identity in five regions

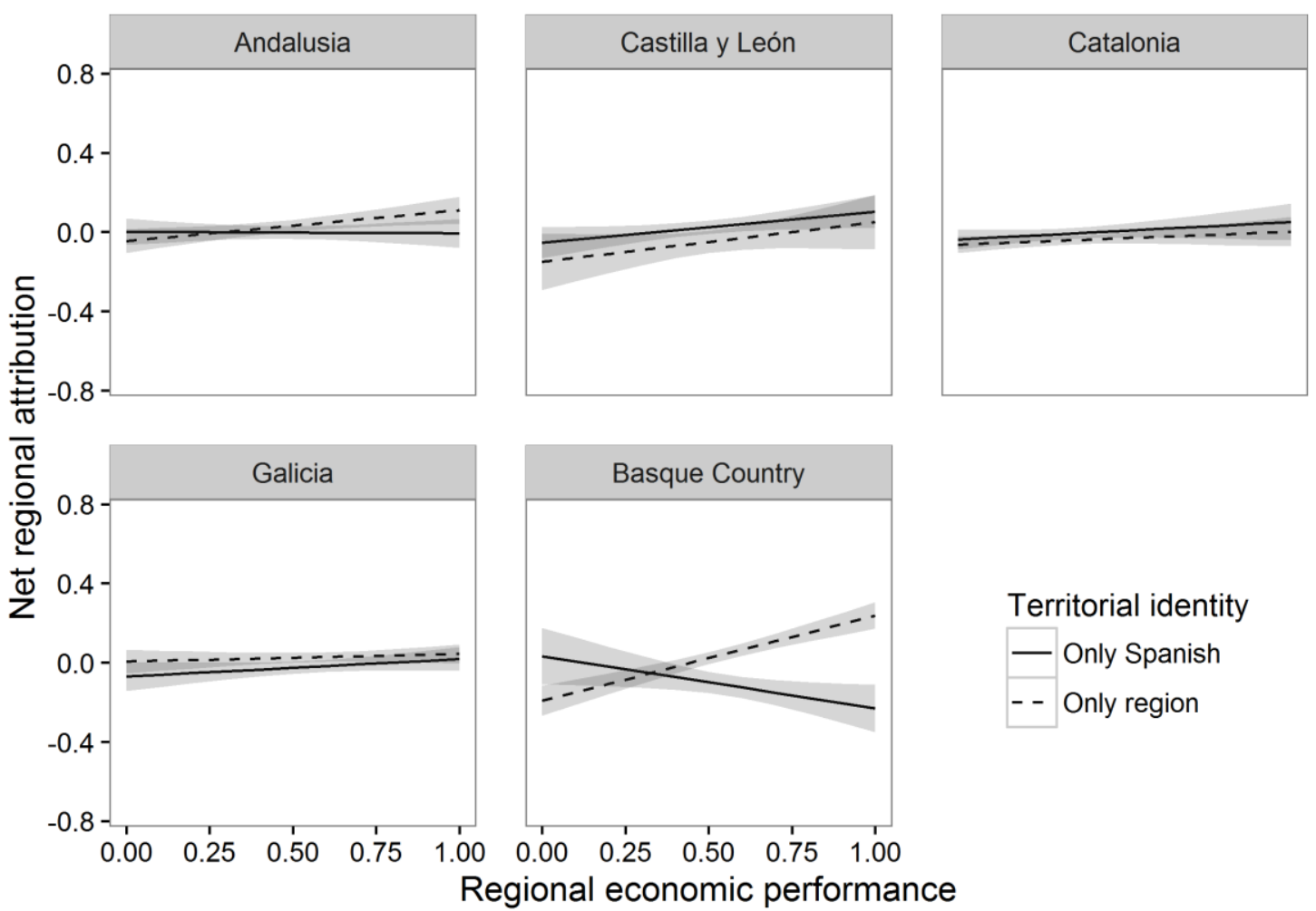

Note: predicted values and 95\% confidence intervals based on the estimates in Table 4. 